\title{
Response of moorland vegetation to 20 years of conservation management in two Cairngorm glens
}

\author{
David Welch*; David Scott \\ Centre for Ecology \& Hydrology, Edinburgh Research Station, Bush Estate, Penicuik, \\ Midlothian, EH26 0QB.
}

*Corresponding author: David Welch, email: dwe@ceh.ac.uk

This pdf constitutes the Version of Record published on $11^{\text {th }}$ February 2019.

\begin{abstract}
The response of vegetation to a large reduction in red deer numbers was assessed over a 20 year period in two contrasting glens in the Eastern Cairngorms. Monitoring was done in spring when the annual maximum herbivore impact accumulates on the heather. We estimated deer presence from pellet-group counts, and for heather we measured cover, height and shoot browsing. Deer numbers declined earlier in Glen Derry, and correspondingly heather height increased sooner. Trends in Glen Lui were related to plot wetness and distance from places where the deer were fed in winter; dry plots received much heavier usage from deer and rabbits initially, keeping the heather short and cover stable, whereas on wet plots usage was much lower and heather increased both in cover and height. Subsequently, as deer densities fell, the Lui heather thrived, and by 2013 heather height on dry plots had surpassed height on wet plots. Colonisation by pine saplings was very patchy, being virtually confined to plots within $50 \mathrm{~m}$ of mature trees and having heather swards less than $25 \mathrm{~cm}$ tall. Despite deer numbers falling, saplings still suffered browsing by black grouse, lagomorphs and voles. Annual increments were greatest on dry plots in Glen Lui. However, we estimate that another eight years of negligible deer numbers are needed for the present sapling crop to become safe from deer damage. A limited regime of burning near mature pines may assist regeneration.
\end{abstract}

Key Words: heather; plant communities; red deer; Scots pine; uplands; woodland regeneration

\section{Introduction}

Which landscapes and vegetation types are wanted in the British uplands is currently receiving much debate, with widely divergent options advocated by different organisations, landowners, and the general public. Some want attractive open landscapes for recreation, some want sporting use including deer stalking and grouse shooting, some want agricultural production, some want the conservation or restoration of habitat types that have become rare in recent times, some want wildness with no noticeable human impacts, and several other demands and outputs are locally important. A new review on upland management in Scotland (MorganDavies et al., 2015) employed two dichotomies in considering these uses: 
management either for "the few" or for "the many" and management either for an output of consumables or for providing non-consumable values or "delights". The authors documented a recent swing towards "delights for the many" that now influences much upland management, so no longer do a few owners with large estates control the Scottish uplands exclusively for their own purposes.

To achieve any of these diverse objectives, knowledge is required on the response of the main upland vegetation types to different management regimes, especially if they develop into different communities, and on the time scale of such successions. Much is now known about the Scottish uplands, as shown by the wide variety of papers included in a book edited by Thompson et al. (1995), but these studies deal largely with cultural moorlands managed by burning. In such moorlands the natural successions to woodland are prevented in order that dwarf shrubs particularly heather (Calluna vulgaris) can flourish and provide good food and habitat for livestock and game birds, these being agricultural or sporting managements.

For a recovery of native woodlands in the uplands and/or a return to wilderness or wildness, it is very desirable to know how long it takes for native broad-leaved trees or Scots pine (Pinus sylvestris) to establish themselves sufficiently that regeneration cannot be halted or reversed by grazing animals, and what herbivore densities allow these successions to progress. But very few such assessments have been made (Miles et al., 1978; Marrs \& Welch, 1991; Rao, 2017), mainly because such successions have been confined to a very small proportion of all upland ground and their slowness makes continued observation difficult and costly to sustain. Also, the time scales estimated for woodland establishment have been very variable, ranging from around 10 years to more than 50 years (Marrs \& Welch, 1991).

The key species affecting or checking successions in much British moorland is Calluna vulgaris, and so most studies on moorland vegetation dynamics have concentrated on it (Legg, 1995). The cover and height of heather control the graminoid and herbaceous species present (Harris et al., 2011; Welch \& Scott, 1995) and can prevent the initial establishment of tree saplings. In the former study the time scale of heather change was deduced by examining c. 1000 burnt patches 2-18 years-old in five Peak District moorlands, cover and height being found to be directly and closely related to the time elapsed since burning, and the cover and number of subsidiary species was inversely related to heather height. But herbivore grazing was not assessed, tree saplings did not colonise, and the authors lamented that "so little is known about moorland post-fire succession" in Britain.

Long-term monitoring of heather performance and tree colonisation on the Mar Lodge Estate in the Cairngorms is providing further evidence about moorland successions, and is reported in the present paper. Partly the observations have been enabled because the National Trust for Scotland, the owners of the estate since 1995 , have had a policy of no burning in the study glens in order to give a greater feeling of "naturalness" for the many visitors. The monitoring began in two glens in 1991 following much concern about the intense pressure of high numbers of red deer (Cervus elaphus L.) on the estate moorlands and especially the lack of regeneration of the native Caledonian pinewoods. The Mar Lodge Estate then contributed a major proportion of the total deer in the Cairngorms and West Grampian Deer Management Group, and counts by the Red Deer Commission had shown a large increase in number over the previous two decades (Callander \& 
Mackenzie, 1991). So there was a conservation-led demand for an assessment of this deer impact, in the hope that showing "damage" would encourage a reduction in red-deer numbers.

Hence base-line data about the heather state under intense grazing was obtained in 1991-1995 before the new ownership increased the deer cull on most of the Mar Lodge Estate, and heather recovery started in Glen Derry and Glen Lui. A first paper (Welch et al., 2006) described the heather trends up to spring 2001 that had resulted from the initial reduction in deer grazing, and some separate monitoring of colonising pine saplings was described by Rao $(2011 ; 2017)$. The present paper reports the heather trends and tree colonisation up to 2015 in the two glens on 186 plots monitored since 1991.

\section{Study areas}

The two study areas lay along rivers in topographic basins with high mountains around. The areas were chosen since red deer congregated in them for much of the year and could readily be counted there; the counts checked the validity of dung assessments of presence.

Table 1. Initial state of the two study areas recorded in spring 1992 from 96 monitoring plots in Glen Derry and 90 plots in Glen Lui. For the index of soil wetness, scores of 1 (dry), 2 (moist) and 3 (wet) were given to plots.

$\begin{array}{lcc}\text { Overall size (ha)* } & 239 & 202 \\ \text { Extent of Calluna heath (ha) } & 202 & 155 \\ \text { Extent of riverside grasslands (ha) } & 37 & 47 \\ \text { Altitudinal range (m above sea-level) } & 490-700 & 400-540 \\ \text { Mean index of soil wetness } & 2.4 & 1.4 \\ \text { Sampling circles with heather present (\%) } & 67 & 73 \\ \text { Mean height of heather (cm) } & 25 & 17 \\ \text { No. of sampling plots with: } & 23 & \\ \text { Heather height < } 20 \mathrm{~cm} & 17 & 43 \\ \text { Heather height > 30 cm } & 23 & 4 \\ \text { Mature Scots pines within } 50 \mathrm{~m} & 0 & 3 \\ \text { Scots pine plantations of } 1971 \text { within } 50 \mathrm{~m} & & 16 \\ \text { * excludes tree exclosures planted in } 1971 \text { and 1989/90 occupying c. } 20 \text { ha in } \\ \text { each area. }\end{array}$

Details of both areas are given in Table 1 and their positions within the Mar Lodge Estate are shown in Fig. 1. Both areas had extensive flat terraces by the central rivers, but only in Glen Derry were these heather-dominated. The Lui terraces were mostly grasslands lacking heather and had been cultivated in the eighteenth century; afterwards they were fertilised to maintain rich grazing for livestock. The study areas were largely treeless but some remnant individual old trees of Scots pine grew in the southern half of the Glen Derry area; in the Glen Lui area remnant old pines were even fewer and confined to the South corner. However, 
several small exclosures within and near the Lui area had been planted with conifers in the early 1970s (Scott, 1998).

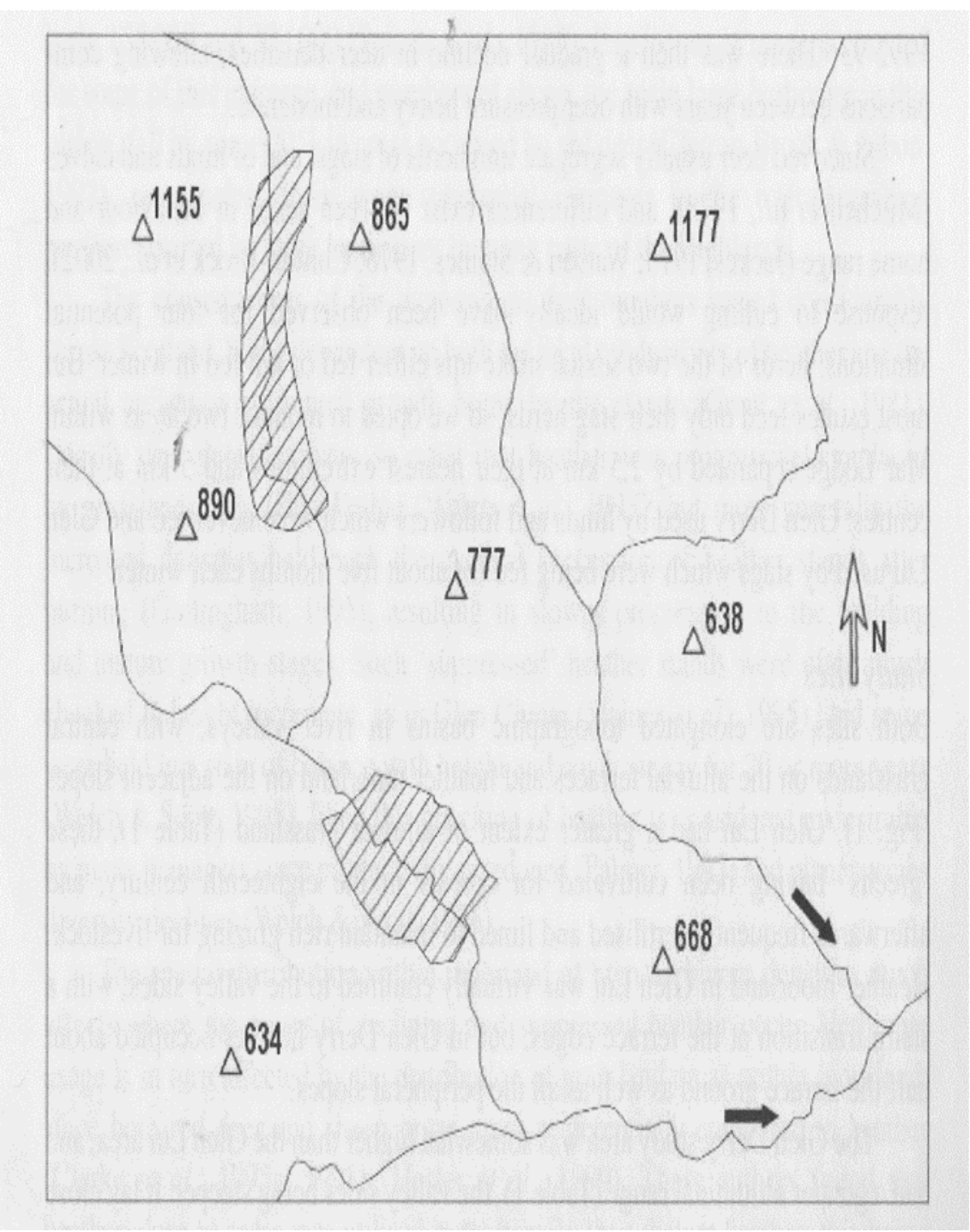

Figure 1. Position and shape of the two study areas (hatched: upper, Glen Derry; lower, Glen Lui) in valleys of the Eastern Cairngorms. Arrows show direction of river flow. Surrounding peaks have altitudes given in metres. Map size is $13 \times 11$ km; the bottom SW corner is at NO 000890 on the British National Grid.

The Glen Derry monitoring area was the higher in altitude, being both upstream from Glen Lui and having steeper valley sides. It had a greater extent of wet soils, mainly peaty gleys, and drier podsols were largely confined to its steep eastern flank. The peaty gleys mostly bore Erica tetralix wet heath (National Vegetation Classification (NVC) M16; Rodwell, 1991), with local Scirpus cespitosus Erica tetralix NVC M15 wet heath, and on patches of deeper peat there was Erica tetralix - Sphagnum papillosum mire NVC M18. The podsols supported Calluna vulgaris - Vaccinium myrtillus NVC H12 heath, and parts of the central alluvial terraces had Nardus stricta - Galium saxatile NVC U5 grassland. Nardus stricta also 
was locally dominant in the far north-east corner of the Derry area in flushed ground above the $600 \mathrm{~m}$ contour.

The Glen Lui monitoring area had extensive podsols on its sloping flanks bearing Calluna vulgaris - Vaccinium myrtillus NVC H12 heath. South-west of the river there was a tract of wetter ground with peaty podsols and gleys, the vegetation being predominately Erica tetralix wet heath NVC M16. The central alluvial grasslands lacking Calluna were not monitored in this area.

Deer were regularly fed on the Lui riverside grasslands in winter until 2001, and our counts confirmed that almost all the deer using the Lui area were stags, in line with the male-female dichotomy that had long existed in this part of the Eastern Cairngorms. The Glen Derry area was in hind ground, and stags moved into it mostly in the autumn rut.

In 1992 heather cover was greater in Glen Lui, with mean occurrence $73 \%$ in the 8-cm diameter sampling circles as opposed to $67 \%$ in Glen Derry (Table 1) (see Methods). But the heather was somewhat taller in Glen Derry, averaging $25 \mathrm{~cm}$ height as opposed to $17 \mathrm{~cm}$ in Glen Lui. In Glen Derry $18 \%$ of the monitoring plots had heather initial heights greater than $30 \mathrm{~cm}$ and a few plots had initial mean heights of $50 \mathrm{~cm}$. In Glen Lui almost half the plots had suppressed heather with mean heights less than $20 \mathrm{~cm}$ in 1992, and $40 \mathrm{~cm}$ was the maximum initial height there.

Burning of heather had formerly been the normal management practice on Mar Lodge Estate, but aerial photographs taken in 1946, 1961 and 1966 indicated its frequency was declining and 1989 photographs showed very little ground had been burnt in the previous decade. This probably reflected much heather being in a suppressed state due to the rising deer population. After 1990 only a tiny section of moorland was burnt in the monitoring areas due to an accidental fire.

\section{Methods}

Permanent monitoring plots were set up in winter 1991-1992 and then visited each spring. The plots were equally spaced on grids covering the whole of both monitoring areas except the riverside grasslands in Glen Lui (Fig. 1). Plot size was 15 x $4 \mathrm{~m}$; there were 96 plots in Glen Derry and 90 in Glen Lui.

The regular monitoring was of 1 ) deer and lagomorph usage and 2) heather cover, heather height and heather shoot damage from browsing. Additionally, the plots were assessed in the first two springs for soil wetness (wet, moist or dry), and in 1998 and 2001 the annual growth increment of heather was measured on 15 shoots per plot. Deer usage was estimated by counting the total number of pellet groups on the plots, and hare and rabbit usage was recorded on a 3-point index scale, dividing at mean densities of 8 and 25 pellets $\mathrm{m}^{-2}$. Assessments on heather cover and shoot browsing were made using a sampling stick that had four $8-\mathrm{cm}$ diameter circles. It was placed at ten positions in each plot, these arranged in two parallel rows along the plots lying alternately at $45^{\circ}$ to the left and right of the plot axis, hence 40 circles were examined per plot. All the circles were checked for the presence of any green shoot of heather to give a cover index, and in the first four circles with heather present we counted browsed and unbrowsed long shoots to give a measure of shoot utilisation. Mean height was estimated from $c .25$ ruler measures spread evenly in all the heather patches on a plot. 
Observations on saplings of Scots pine began in 1997. When the study was planned it was not envisaged that deer numbers would be reduced sufficiently to allow tree regeneration, but by 1996 this had become a management objective and a few sapling pines were seen on our plots in Glen Derry, deer numbers having fallen there. From 1998 onwards the heights of saplings were measured in Glen Derry and their positions on plots were mapped. In 2000, systematic observations were extended to the Glen Lui plots, and any visible saplings were recorded whatever the tree species. Our counts were not an absolute count of seedlings and saplings since these are too small to be noticed within the taller heather of most plots until they are at least three or four years old; many very young seedlings die due to competition and shading, and once bigger they suffer browsing from black grouse, lagomorphs and voles as well as deer. Therefore the counts merely provide an index of potential tree colonisation. In later years large numbers of pine saplings appeared on a handful of plots, and then we measured only the taller ones for height. Many plots with saplings lay close to mature Scots pines, and Chi-square tests were used to assess the significance of the association.

After 1996 yearly observations on heather cover were considered unnecessary, mean values having been found to change little from year to year. A further cut-back to reduce the time required to do the monitoring started in 1999, only half the plots in each glen being visited that year and in some later ones. These plots were spread across the monitoring areas and chosen to ensure that the mean values recorded in the reduced sampling were virtually identical to the means obtained on all plots. For the figures and tables reported here, heather cover and utilisation means are given only for the years when all plots were visited, but for herbivore usage means are given for every year, the variability resulting from the reduced sampling being considered negligible.

To assess the impact of herbivores on heather, the study years were divided into four successive periods with progressively declining usage; end dates were chosen for these periods when full sampling was available. The significances of changes in heather cover and height were assessed for each period using paired ttests that compared the plot data obtained in the first and last years of these periods. For Glen Lui, the impact of the deer being fed on the central grasslands until 2001 was assessed by assigning plots to four zones defined by distance from the grasslands and comparing zonal usage and heather data between the periods before and after 2001. For the dung index and heather utilisation, zone year means in the two periods were compared using paired t-tests; for cover and height change, plot measurements obtained in the first and last years of each period were compared by paired t-tests in each zone.

Nomenclature follows Stace (2010) for vascular plants, Rodwell (1991) for plant communities, and Smith (2006) for mosses.

\section{Results}

Usage by deer and lagomorphs

Usage by deer measured from the spring counts of pellet groups fell greatly during the 24-year study period (Fig. 2). Numbers of pellet groups began to fall in 1995, and for the next seven years usage was much less in Glen Derry than Glen Lui. A very sharp decline between 2001 and 2002 in Glen Lui reflected not only increased culling but also the cessation of winter feeding on the central grasslands; hay, 
carrots or potatoes spread every day or two days in winters till 2000 had attracted many stags which, after their feeding bout, moved onto the surrounding heather moorland. Both red-deer and roe-deer pellet groups contributed to the count totals, but numbers of the latter were negligible. After 2008 an intensification in the culling of stags brought usage down to similar very low levels in both glens.
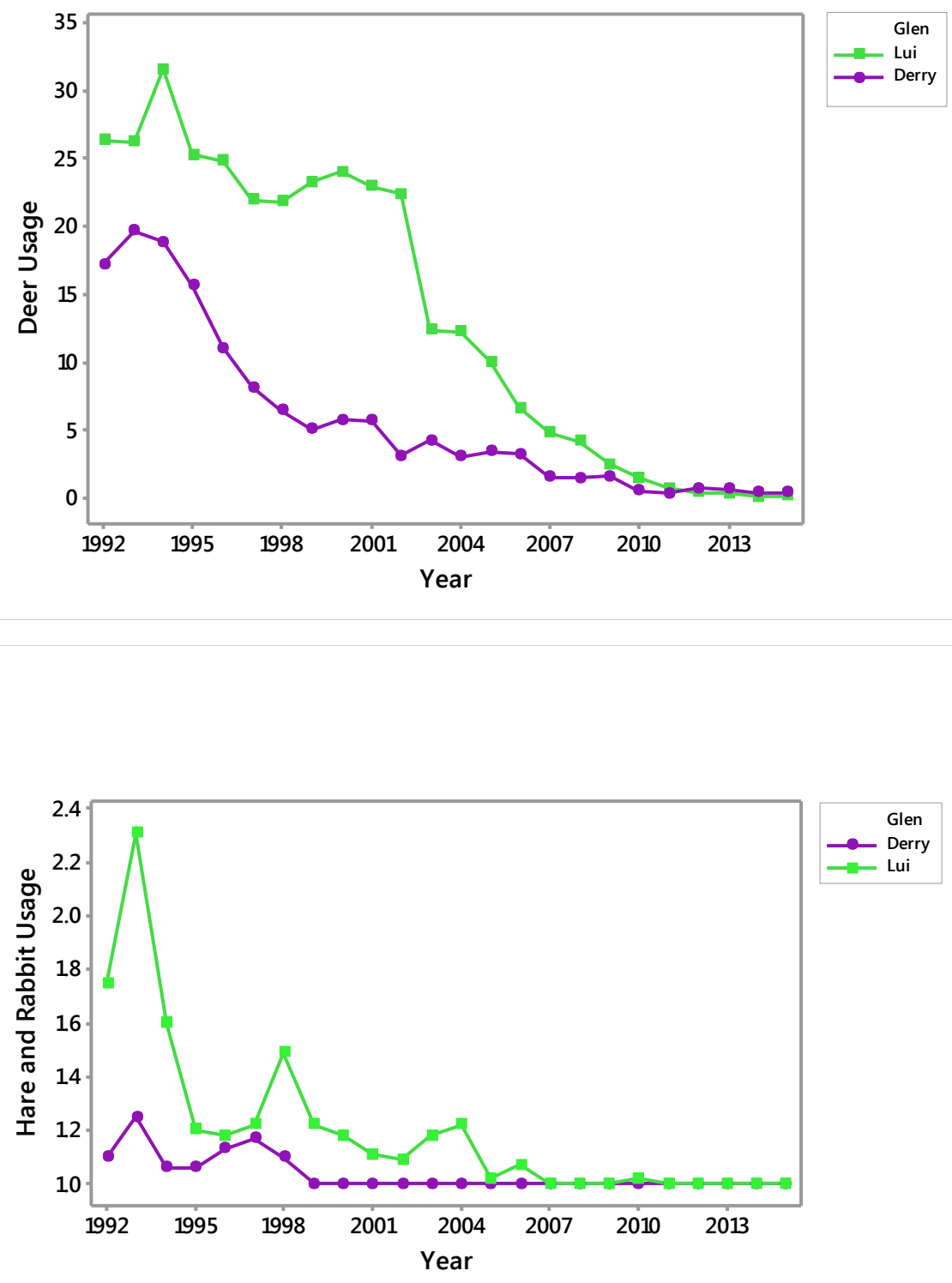

Figure 2. Usage by deer (upper) and lagomorphs measured in springs of 24 years (1992-2015) in the two glens. Deer usage is the mean number of pellet groups counted on $60 \mathrm{~m}^{2}$ plots; lagomorph usage is an index showing mean occurrence of $>\mathbf{8}$ hare and rabbit pellets per $\mathbf{m}^{2}$.

Lagomorph usage was mainly by mountain hares (Lepus timidus L.) in Glen Derry, but in Glen Lui there were great numbers of rabbits (Oryctolagus cuniculus L.) in the early years of the study. Intense shooting then brought down the rabbit population, and possibly severer winter weather than in 1990-1993 period caused 
greater natural mortality. Usage by both species has been light since 2000, but hares remain present throughout both study areas.

\section{Trends in heather utilisation}

The percentage of heather long shoots incurring browsing fell substantially during the study (Fig. 3). Initially, mean utilisation was about a third less in Glen Derry than Glen Lui. This difference increased up to 2000, reflecting the divergence observed in deer numbers. In Glen Lui wet plots had much lower utilisation than drier ones, partly due to deer usage but also to rabbit grazing; rabbits were confined to the drier parts of this glen. In Glen Derry three of the monitoring plots were classed as dry but had utilisation and deer usage no different to the moist plots, hence these types have been pooled and are named moist in this paper.

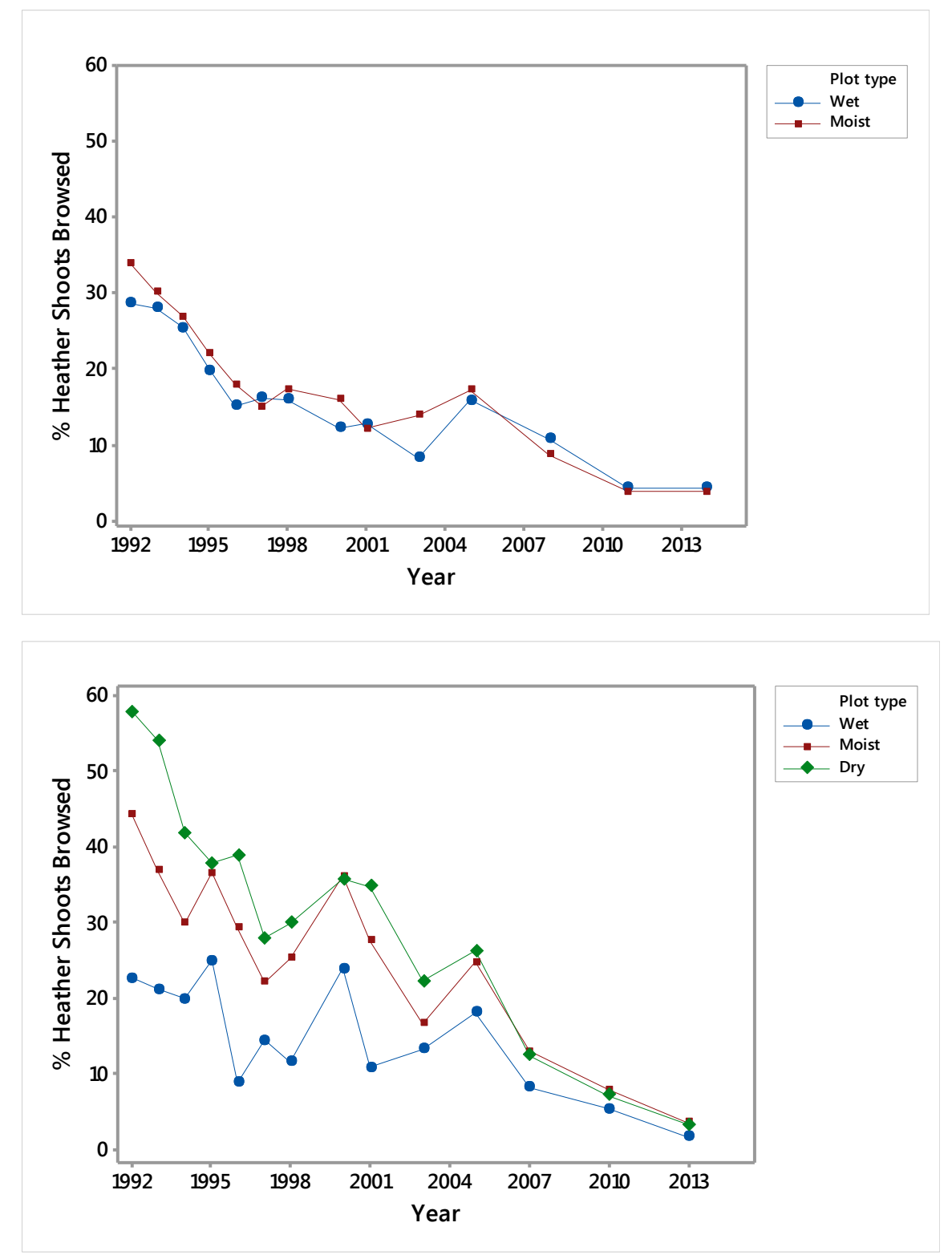

Figure 3. Trends in heather utilisation in Glen Derry (upper) and Glen Lui for plot types. 
Trends in heather cover and height

Initially heather cover was quite variable, with some sampling plots having only a few circles with heather present and other plots having all 40 circles occupied. But mean heather cover was lower on the wet plots in both glens, and heather changed much less in mean cover in Glen Derry (Fig. 4). This is reflected by the difference between glens in the number of significant cover increases found for the successive observation periods defined on declining deer usage (Table 2). In Glen Derry the overall 22-year increase in the percentage of sampling circles having heather present was just 3\%; this was calculated from means of 26.9 and 28.1 circles containing heather out of 40 in 1992 and 2014 respectively. The only significant change for Glen Derry was for all 96 plots in the 1997-2001 period $(P<0.01)$.
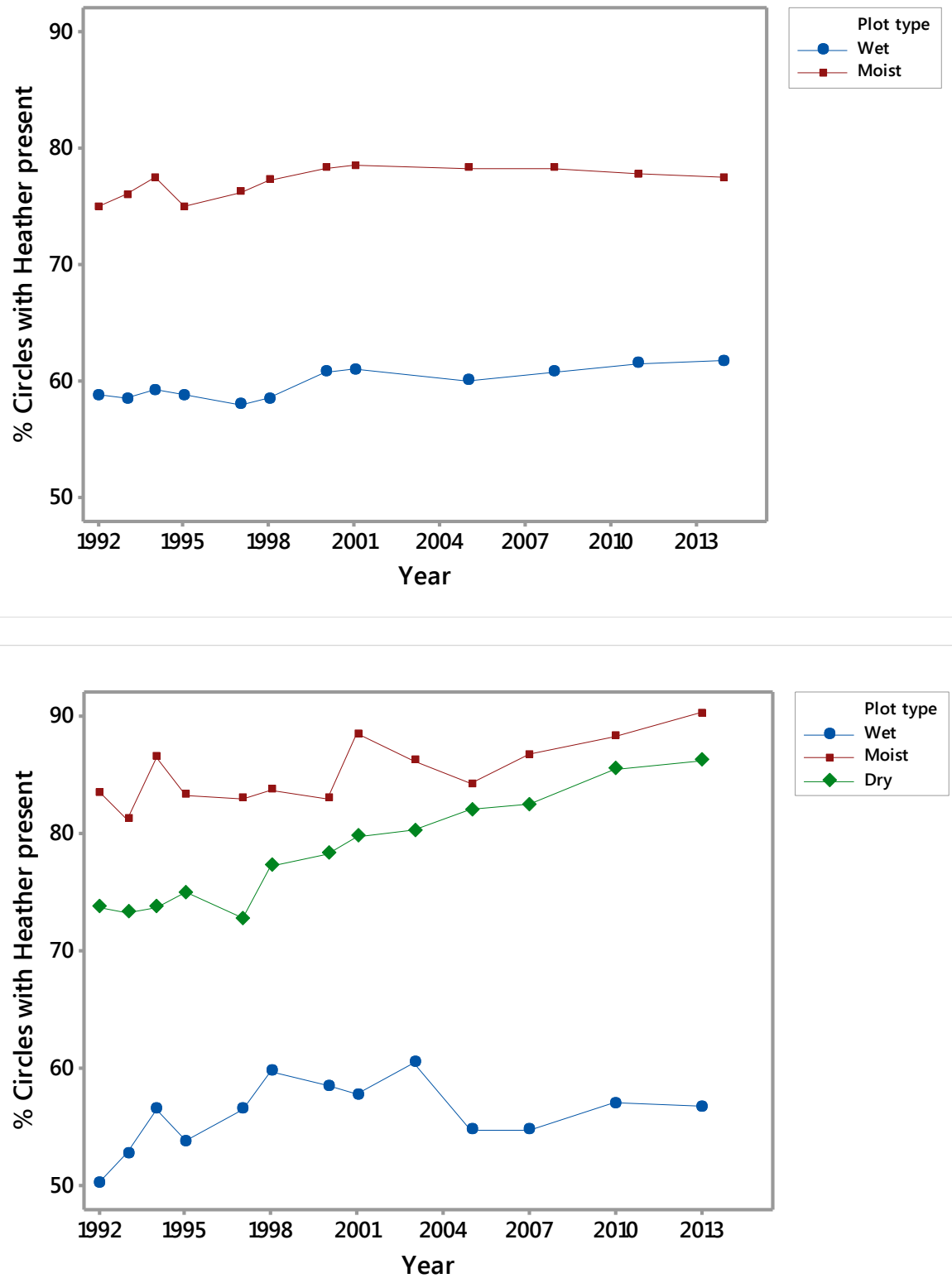

Figure 4. Trends in heather cover in Glen Derry (upper) and Glen Lui for plot types. 
In Glen Lui the cover of heather declined slightly on moist and dry plots up to spring 1997, reflecting the heavy initial deer usage there (Fig. 4, Table 2). On wet plots with lower deer usage, heather cover increased. After 1997, there was a persistent and substantial increase in cover on the 61 dry plots. By the last years of the study many plots in Glen Lui had heather present in all 40 sampling circles, limiting the possible increase measurable by our index.

Table 2. Heather changes in the two study glens in four successive periods of declining deer usage. Significances are given for changes between the first and last spring of each period $(\boldsymbol{P}<0.001 * * *, P<0.01 * *, P<0.05 *)$ calculated from a paired t-test on all available plots. For cover index, changes are expressed as increases or decreases in the mean percentage of $8-\mathrm{cm}$ circles with heather present; deer usage is the mean number of pellet groups on $60 \mathrm{~m}^{2}$ plots observed in all springs of the four periods.

\section{Glen Derry}

Heather Cover Index:

$\begin{array}{llllll}\text { All plots }(\mathrm{n}=96) & +0.3 & +2.5 & * * & 0.0 & +0.1 \\ \text { Wet plots }(\mathrm{n}=46) & -0.8 & +2.9 & & -0.3 & +1.0 \\ \text { Moist plots }(\mathrm{n}=50) & +1.3 & +2.3 & & +0.3 & -0.7 \\ \text { eather Height }(\mathrm{cm}): & & & & & \\ \text { All plots } & +3.4 * * * & +0.9 & * & +1.5 * * * & +1.6 * * * \\ \text { Wet plots } & +2.6 * * & 0.0 & & +1.1 * * & +1.4 * * \\ \text { Moist plots } & +4.1 * * * & +1.7 & * * & +1.9 * * * & +1.7 * * *\end{array}$

Deer Usage:

All plots

Wet plots

14.6

5.7

2.8

0.7

12.4

5.5

2.8

0.7

Moist plots

16.7

5.9

2.9

0.7

\section{Glen Lui}

1992-1997 1997-2001 2001-2007 2007-2013

Heather Cover Index:

All plots $(n=90)$

Wet plots $(n=11)$

Moist plots $(\mathrm{n}=18)$

Dry plots $(n=61)$

Heather Height (cm):

All plots

Wet plots

Moist plots

Dry plots

Deer Usage:

All plots

Wet plots

Moist plots

Dry plots

\begin{tabular}{|c|c|c|c|}
\hline $\begin{array}{r}0.0 \\
+6.2 \\
-0.6\end{array}$ & $\begin{array}{l}+6.0 * * * \\
+1.4 \\
+5.5 * * \\
+6.9 * * *\end{array}$ & $\begin{array}{l}+1.1 \\
-2.9 \\
-1.9 \\
+2.5\end{array}$ & $\begin{array}{l}+3.5 \text { ** } \\
+2.1 \\
+3.6 \\
+3.7\end{array}$ \\
\hline $\begin{array}{l}0.6 \\
3.6 * * * \\
1.7\end{array}$ & $\begin{array}{l}+1.3 * * * \\
0.0 \\
+2.5 * \\
+1.4 * *\end{array}$ & $\begin{array}{l}+2.5 \text { *** } \\
+1.4 \\
+2.5 \\
+2.7 * *\end{array}$ & $\begin{array}{l}+0.1 \\
+3.2 \\
+5.8 \\
+7.6\end{array}$ \\
\hline
\end{tabular}

22.9

11.4

1.6

10.4

9.4

6.2

0.6

26.9

22.6

12.0

2.1

28.4

25.4

12.1

1.6 
Heather height was initially greater in Glen Derry than Glen Lui, and on wet plots than drier ones (Fig. 5), in line with the deer and lagomorph usage then being incurred (Fig. 2). In Glen Derry height increased steadily throughout the study, more so on the 50 moist plots than the 46 wet ones, the latter gains being less significant (Table 2). In Glen Lui there was likewise greater increase in height on the dry and moist plots than on wet ones, and by the last year of recording the dry plots had overtaken wet plots in mean height. The dry plots had no increase in mean heather height up to 2000, but then in parallel with the falling deer usage these plots experienced an increasingly rapid height gain (Fig. 5).
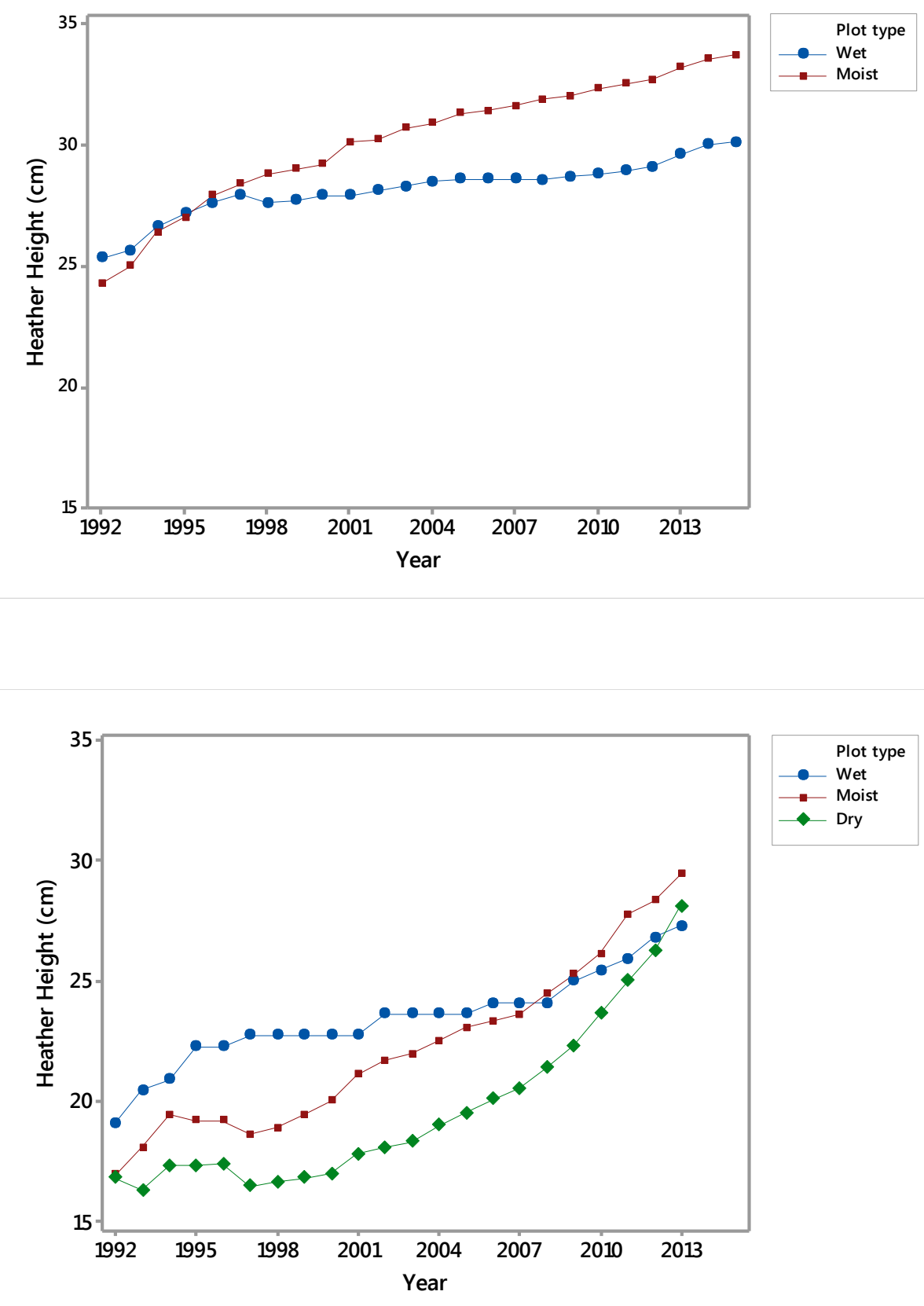

Figure 5. Trends in heather height in Glen Derry (upper) and Glen Lui for plot types. 
Heather trends in Glen Lui were also related to the zonation of deer usage observed during the years when supplementary feeding occurred (1992-2001; Table 3). Height increased significantly from 1992 to 2001 only in the peripheral zone to the central grasslands ( $>300 \mathrm{~m}$ distant), and this zone then had significantly less deer usage $(P<0.001)$ and heather percentage shoot browsing $(P<0.001)$ than the other three zones (paired t-tests). For the 2001 to 2013 period with no feeding and lower overall deer usage, heather height increased sharply in all four zones but less in the peripheral zone. Gains in cover were smaller in this second period than the first for three of the zones.

Annual growth mean increments of the heather were smaller in Glen Derry (2.2 $\mathrm{cm})$ than Glen Lui $(3.6 \mathrm{~cm})$. No difference was found between moist and wet plots in Glen Derry, but in the Lui area growth was respectively $3.9 \mathrm{~cm}, 3.3 \mathrm{~cm}$ and $2.9 \mathrm{~cm}$ on dry, moist and wet plots.

Table 3. Comparison of impact zonation between periods before and after deer supplementary feeding ceased in Glen Lui. Plots are grouped by their distance from the central alluvial grasslands where feed was regularly delivered in winter. Measurement units and significance tests are the same as in Table 2.

\begin{tabular}{|c|c|c|}
\hline \multirow{2}{*}{ Heather Cover Index: } & $1992-2001$ & \multirow[t]{2}{*}{ 2001- } \\
\hline & & \\
\hline Adjacent plots $(n=25)$ & $+6.7 * *$ & +3.8 \\
\hline Close plots $(n=16)$ & +8.3 & +9.7 \\
\hline Intermediate plots $(n=17)$ & $+6.8 * *$ & +6.2 \\
\hline Peripheral plots $(\mathrm{n}=32)$ & $+3.8 * *$ & +1.9 \\
\hline \multicolumn{3}{|l|}{ Heather Height $(\mathrm{cm})$ : } \\
\hline Adjacent plots & -0.2 & +11.6 \\
\hline Close plots & +0.9 & +10.9 \\
\hline Intermediate plots & 0.0 & +10.9 \\
\hline Peripheral plots & $+4.7 * * *$ & +6.0 \\
\hline \multicolumn{3}{|l|}{$\%$ Heather Shoots Browsed: } \\
\hline Adjacent plots & 47.5 & 18.7 \\
\hline Close plots & 42.4 & 14.0 \\
\hline Intermediate plots & 38.7 & 13.9 \\
\hline Peripheral plots & 21.8 & 9.1 \\
\hline \multicolumn{3}{|l|}{ Deer Usage: } \\
\hline Adjacent plots & 29.2 & 8.4 \\
\hline Close plots & 26.8 & 6.6 \\
\hline Intermediate plots & 30.3 & 7.4 \\
\hline Peripheral plots & 16.7 & 3.4 \\
\hline
\end{tabular}

\section{Tree colonisation}

Almost all the saplings observed on the monitoring plots were Pinus sy/vestris. Just eleven small saplings of three other tree species, Larix decidua, Sorbus aucuparia, 
and Salix cinerea, were found on the plots, some of them surviving for just one or two years. However tiny bushes of Juniperus communis occurred on several plots in Glen Derry and although not measured, they seemed to make no gain in height and were suffering repeated browsing.

Pine saplings appeared sooner in Glen Derry than Glen Lui (Fig. 6). Up to 1998 there was mostly only a single sapling on a plot and many were not found the following spring, hence the initial variability in the percentage of plots with saplings. After 2001, sapling numbers increased and 7 of the 96 Derry plots had saplings present throughout the rest of the study, though few further plots were colonised. By 2015 there were 95 saplings on 11 plots. Most of the 18 plots that at some time had saplings were at the south end of the Glen Derry area close to tall old pines: 11 of the 18 lay within $50 \mathrm{~m}$ of old pines and almost all the post-2001 increase in sapling number was on them. The association of sapling presence on plots and old pines being $<50 \mathrm{~m}$ distant was highly significant (Chi-sq $=16.8, \mathrm{P}<0.001)$, and plots situated $>50 \mathrm{~m}$ from old pines contributed very little to the sapling total having at most 2 saplings present in any recording.

In Glen Lui pine saplings were observed only twice on monitoring plots before 2008 (Fig. 6). Then steady colonisation began on two plots and by 2014 these plots contributed 206 out of the 238 total saplings. The two plots lay within $20 \mathrm{~m}$ of exclosures planted with pines and other conifers in 1971, and another four plots on which saplings appeared in 2009-2011 were less than $50 \mathrm{~m}$ distant to mature pines producing cones; the association of sapling presence on plots with mature pines being $<50 \mathrm{~m}$ distant was highly significant (Chi-sq $=11.2 \mathrm{P}<0.001$ ), as in Glen Derry. However, 11 of the 19 plots situated inside this $50 \mathrm{~m}$ radius zone were never found to have saplings.

The heights of the saplings increased only very slowly in Glen Derry, due to regular browsing. By 2009, the average of top heights on all plots with saplings had only reached $14.1 \mathrm{~cm}$, a rise of $0.5 \mathrm{~cm}$ since 1998 (Fig. 7). The year means came from 11 plots, but due to sapling deaths and new occurrences only 6 plots were common to 1998 and 2009. From 2009 to 2015 the same 11 plots kept saplings and mean top plot heights rose by $8.5 \mathrm{~cm}$. The turnover of saplings meant very few individuals were recorded for more than ten years, but the 6 saplings on 4 separate plots present for 11 years from 2003 had mean heights of $14.7 \mathrm{~cm}$ (2003), $14.8 \mathrm{~cm}$ (2006), $16.0 \mathrm{~cm}$ (2009), $18.2 \mathrm{~cm}$ (2012) and $20.0 \mathrm{~cm}$ (2014). Setbacks to height increment due to browsing were fewer in later years. However, the top tree of all Glen Derry plots early in the study, that had reached $52 \mathrm{~cm}$ height by 2006, was then thrashed by roe deer, and was dead in 2008, causing the sharp drop that year in top heights (Fig. 7).

In Glen Lui the top saplings gained height steadily (Fig. 7). All but one of those appearing in 2008-2010 were on plots classed as dry, and their annual increments were greater than those of the Glen Derry saplings. Because many new saplings appeared each year once colonisation began in this glen, mean plot heights showed little increase, and so give a poorer measure than the top heights of the time needed to produce definite tree colonisation not liable to be stopped by deer. The tallest Lui sapling, $57 \mathrm{~cm}$ tall in 2015, is not likely to have reached for at least six more years sufficient height to be safe from thrashing or from browsing when snow is deep. 

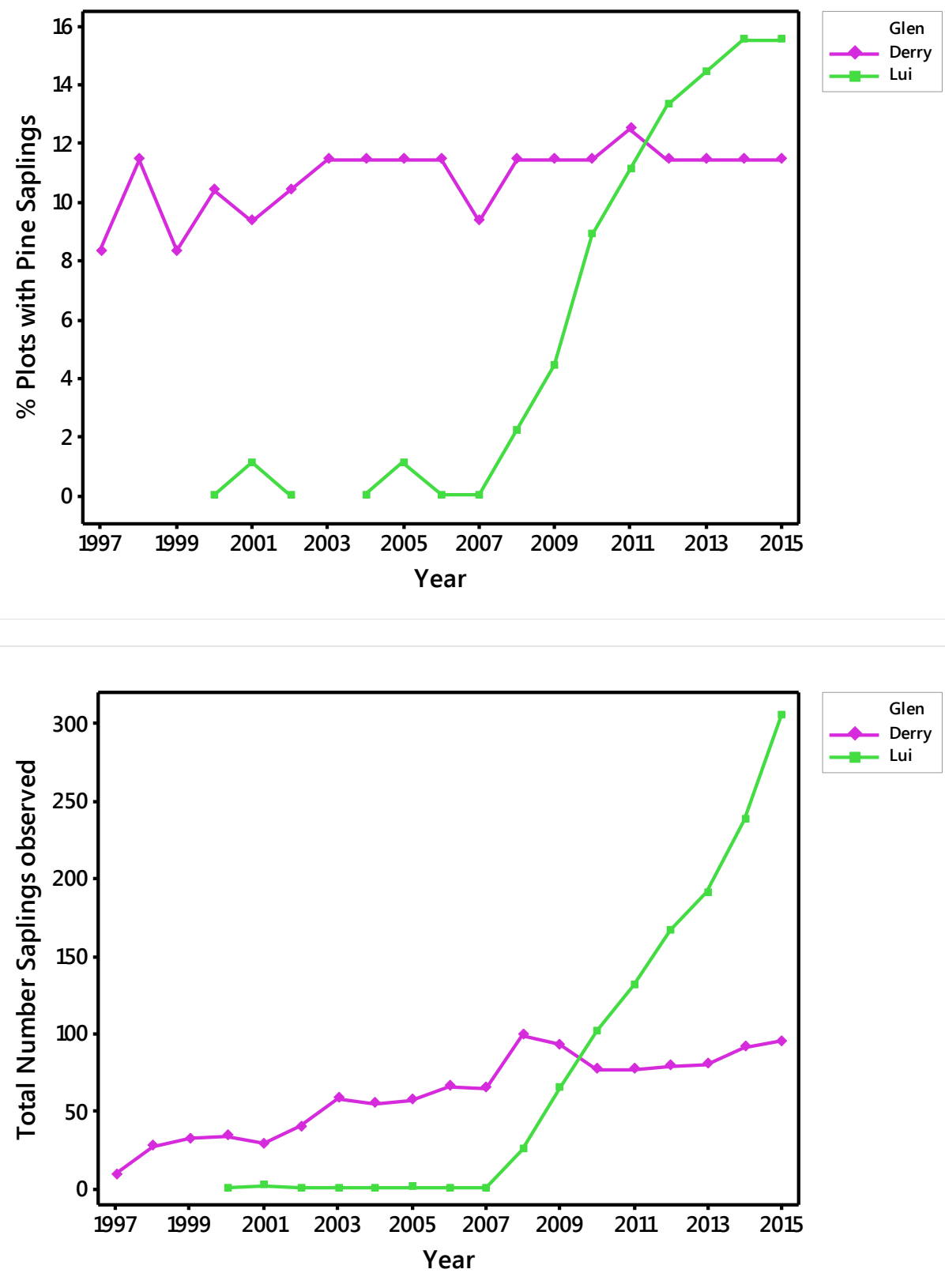

Figure 6. Percentage occurrence on plots of pine saplings (upper) and numbers of saplings observed (lower) for the two glens.

\section{Discussion}

Changes in vegetation composition of the two study areas on Mar Lodge Estate have been minimal despite the low grazing pressure from deer experienced since 2001. On dry soils that mainly carried NVC H12 heath, the increase in the height and cover of Calluna vulgaris (Figs. 4 \& 5) merely made it more dominant. On wet soils that mainly carried NVC M15 Scirpus cespitosus - Erica tetralix heath, the increase in the cover of $C$. vulgaris was much less pronounced, and with presence in only $55-60 \%$ of the 8-cm sampling circles (Fig. 4) there was much space remaining for E. tetralix to flourish; presence in a circle did not mean that a species occupied the whole circle; had we recorded $E$. tetralix in the monitoring it would have had at least as great an occurrence in circles as Calluna on these wet plots. In NVC M15, as noted 
by Rodwell (1991), C. vulgaris has much cover and it is the selective presence of $E$. tetralix, Molinia caerulea, Narthecium ossifragum and Scirpus cespitosus compared to the $\mathrm{H} 12$ dry heaths rather than their dominance that led to the community name. All four species are abundant on wet soils in our two study areas, and being less palatable year-round than $C$. vulgaris (Pollock et al., 2007) they benefit compared to Calluna from the herbivore impact still being exerted. The heather bushes on these wet plots did gain height (Fig. 5) but many are old and moribund, and had few lateral shoots, so there seems little prospect of succession in this community.
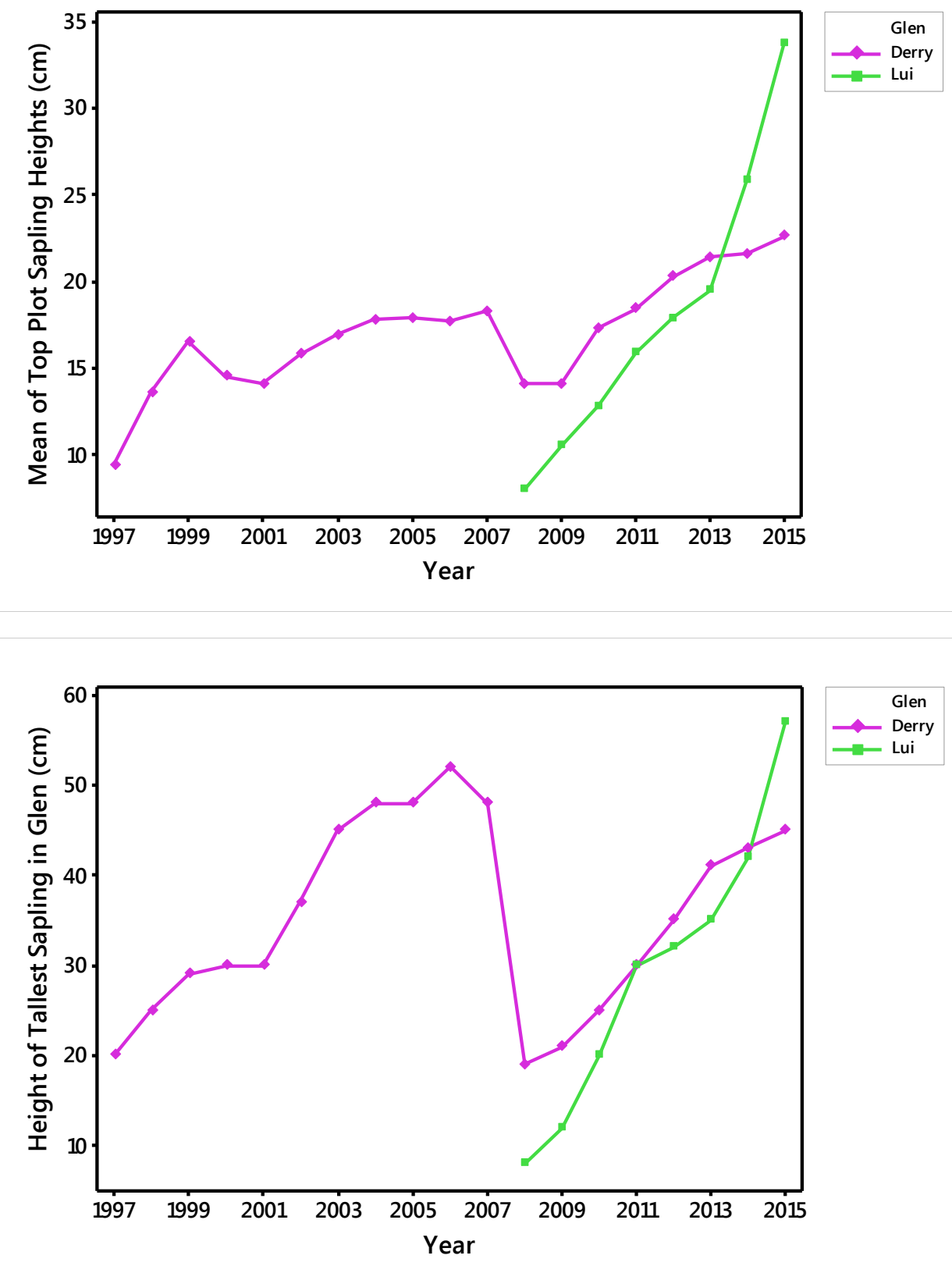

Figure 7. Trends in yearly means of top sapling heights on all plots (upper), and heights of tallest saplings observed each year, in the two glens. Data points from the single occurrences in Glen Lui in 2001 and 2005 are omitted. 
In the dry parts of Glen Lui a potential change from the dominance of heather seemed to be developing C. 2012/2013 when broom (Cytisus scoparius) bushes grew up above the heather and their yellow flowers were visible from a distance. However, the cover of the broom only reached $5 \%$ on a few plots with most colonisation, and the visible shoots were being grazed, probably by hares. Broom is limited to low altitudes in Britain, rarely occurring above $600 \mathrm{~m}$ (Preston, Pearman \& Dines, 2002), and dieback results from low winter temperatures (Peterson \& Prasad, 1998). So succession to broom dominance in Glen Lui therefore seems unlikely.

The heather itself is susceptible to winter die-back; this follows desiccation due to continued transpiration when the ground is deeply frozen (Watson et al., 1966). Die-back has been shown to vary considerably between years on neighbouring moorland (Moss \& Miller, 1976), and a major die-back event was observed at Abernethy $20 \mathrm{~km}$ north of Glen Derry in spring 2003 (Hancock, 2008). Limited heather browning and die-back was seen in most springs in our Mar Lodge monitoring, but we did not measure it and in 2003 only obtained estimates of heather cover in Glen Lui. However, in spring 2004 heather was noted as being in "poor condition" on some plots, and between 2003 and 2005 there was a decline in the cover index on wet plots (Fig. 4). At Abernethy die-back was more severe on flatter ground and where heather had less cover (Hancock, 2008), conditions that apply to our wet plots. So die-back as well as selective grazing, poor growth and old age may contribute to the observed lower overall cover gains on our wet plots; there was actually cover loss on the Lui wet plots from 2001 to 2007 (Table 2) unexpected in view of the low deer usage, and still in 2013 the cover index was lower than in 1998 to 2003 for them (Fig. 4).

Colonisation by sapling Scots pines has started in both Glen Derry and Glen Lui but is currently limited to a very few plots and a considerable further period of negligible browsing from deer will be necessary for it to succeed. Almost all the saplings observed occur within $50 \mathrm{~m}$ of coning pines but plots inside this limit comprise less than a fifth of the overall number monitored (Table 1). One of the two Glen Lui plots with many saplings lies just $15 \mathrm{~m}$ from a plantation of 1971, fitting with observations in the nearby Ballochbuie pinewood that saplings were most numerous within $20 \mathrm{~m}$ of seed sources (Scott et al., 2000). Also important in significantly explaining sapling number at Ballochbuie was low heather height, and similarly in the Northern Cairngorms French et al. (1997) found pine establishment on moorland to be greatest when sward height was less than $20 \mathrm{~cm}$. In the present study there was a similar finding for Glen Lui: the two plots with many saplings had mean heather height of just $10 \mathrm{~cm}$ in 2010, and three more of the seven plots then with such low height experienced colonisation. In Glen Derry plots within $50 \mathrm{~m}$ of seed sources had taller heather (mean height $30 \mathrm{~cm}$ in 2008), which may well have contributed to the sapling numbers being lower there than in Glen Lui.

The trends in plot sapling top heights (Fig. 7) give a rough indication of how long it will take for the pine saplings to reach a height safe from deer damage; we judge this height to be about $180 \mathrm{~cm}$, allowing for deep snow and trunks being strong and thick enough to deter, or survive from, thrashing or bark stripping by deer. In Glen Lui, plot top heights rose by $14 \mathrm{~cm}$ in the two years from 2013, and from our continuing measurements on the Ballochbuie saplings, annual increments could rise to average $20 \mathrm{~cm}$ once the Glen Lui saplings reach $1 \mathrm{~m}$ height. This means it will take, on average, another eight years for the 14 plots currently with saplings 
to have at least one tree reaching safety, and rather less time on the plots with best growth. In Glen Derry, top heights have gained by only about $1 \mathrm{~cm}$ a year since 2010, reflecting the much poorer growing conditions on wet soils at higher altitudes, and doubtless it will take decades there for regeneration to occur away from favourable drier situations. Small mean annual increments of saplings have also been found by Rao (2017) on plots next to mature pines stands on Mar Lodge; increments varied between her study areas but have much increased since 2008.

So a conjunction of at least four circumstances and factors is needed for successful pine colonisation at mid altitudes in the Cairngorms: (1) very low grazing pressure, (2) adult coning trees within $50 \mathrm{~m}$, (3) heather swards of less height than $20 \mathrm{~cm}$, and (4) soils not wet. Although a quarter of the Glen Derry plots and nearly half the Glen Lui plots had heather height less than $20 \mathrm{~cm}$ when the study began (Table 1), by the time that red-deer numbers had fallen suitably low (c. 2002 in Glen Derry and c. 2009 in Glen Lui), these plots comprised just 3\% and 19\% of the total present in the respective study areas. And in Glen Lui only 9 of these 17 plots with low heather lay within $50 \mathrm{~m}$ of pine seed sources.

The National Trust for Scotland in their management planning (2012) recognise the need for more ground to be made suitable for pine establishment in both Glen Derry and Glen Lui, and have considered scarification and heather burning as ways of achieving this. Both will reduce the perception of naturalness for visitors, but heather burning is a very controversial issue at present (Davies et al., 2016), and is likely to be held back until experiments with scarification have started; the 2012 plan says "burning will be explored during the first few years" of intervention work. We consider that small-scale burning around old ancient pines limited to 20-30 m radius from the trees would be acceptable and successful, and suggest that a suitable area for this to be tested is at the south extremity of the Glen Lui area where the soils are dry.

Once patches of regenerated pine trees have been achieved they are likely to give places where red deer can feed, rest and shelter, and control of deer there will be more difficult than in the present open moorland and remnant stands of old pinewood. This should not be considered bad since the deer will regularly emerge and feed in the surrounding heather-dominated moorland. Hence these areas will stay open, still giving visitors attractive views of the surrounding landscape with high mountains. This will ensure that delights for the many (Morgan-Davies et al., 2015) will have been combined with satisfaction to conservationists due to the Scots pine woodland that they greatly value having a safe future on the Mar Lodge Estate.

A drawback of the very light grazing needed to achieve regeneration of the Scots pinewoods is that this has allowed the heather to grow much taller especially on drier soils, and the risk of serious fires has increased. Tall heather now extends across a much larger block of ground than our two study areas, and it would be difficult and costly to reduce fire risk by creating firebreaks within this ground.

This study has ended in its present form, but several elements could usefully be continued to better give answers about the time scale for vegetation change and pinewood colonisation in Cairngorm glens and moorland. The NVC M15 Scirpus cespitosus - Erica tetralix wet heath might develop into a Callunadominated community akin to $\mathrm{H} 12$ with scarce $E$. tetralix if the heather were to increase in cover following its recent height increase; this possibility is suggested by stands of these two types alternating on the west side of Glen Derry. They occur on what 
seem similar soils, and possibly the M15 areas are the result of fires decades ago from which Calluna has recovered much more slowly than Erica tetralix. The possible colonisation of Cytisus scoparius on the dry south-facing slopes of Glen Lui should also be monitored with specific measurements on its cover. These warmer slopes on relatively rich soils should also be watched for the possible colonisation of deciduous trees, rowan (Sorbus aucuparia) being the most likely. But most important is further monitoring is to gain more knowledge on the time scale for Scots pine saplings to reach a safe height from deer damage, and about the plot conditions that allow pine seedlings to colonise within the $50 \mathrm{~m}$ range of pine seed sources. For this, our existing plots could be utilised and extra ones set up.

\section{Acknowledgements}

Too many people have helped in a study lasting 25 years to be named individually, but we are grateful to them all. Mar Lodge staff include Alastair Clunas and David Frew (managers), Stuart Cumming (head stalker), Peter Holden (ranger) and Shaila Rao (ecologist). The planning of the study and its development was guided by Helen Armstrong, Dick Balharry, Charles Gimingham, Angus McDonald and Des Thompson. CEH staff included Brian Staines and Ruth Mitchell, while notable short-term field assistants were Keith Marshall and Anneka Stolte. Kevin Walker, BSBI Head of Science, has painstakingly reviewed our text.

\section{References}

Callander, R.F. \& Mackenzie, N.A. 1991. The management of wild red deer in Scotland. Perth: Rural Forum Scotland, $104 \mathrm{pp}$.

Davies, G.M., Kettridge, N., Stoof, C.R., Gray, A., Ascoli, D., Fernandes, P.M., Marrs, R., Allen, K.A., Doerr, S.H., Clay, G., McMorrow, J., Vandvik, V. 2016. The role of fire in UK peatland and moorland management; the need for informed, unbiased debate. Philosophical Transactions of the Royal Society B, 371: 20150342. https://doi.org/10.1098/rstb.2015.0342

French, D.D., Miller, G.R. \& Cummins, R.P. 1997. Recent development of highaltitude Pinus sy/vestris scrub in the Northern Cairngorm Mountains, Scotland. Biological Conservation, 79: 133-144.

Hancock, M.H. 2008. An exceptional Calluna vulgaris winter die-back event, Abernethy Forest, Scottish Highlands. Plant Ecology \& Diversity, 1: 89-103.

Harris, M.P.K., Allen, K.A., McAllister, H.A., Eyre, G., Le Duc, M.G. \& Marrs, R.H. 2011. Factors affecting moorland plant communities and component species in relation to prescribed burning. Journal of Applied Ecology, 48: 1411-1421.

Legg, C. 1995. Heathland dynamics: a matter of scale. In: Thompson, D.B.A., Hester, A.J. \& Usher, M.B. Heaths and Moorland: Cultural Landscapes, 117134. Edinburgh: HMSO.

Marrs, R.H. \& Welch, D. 1991. Moorland Wilderness: the Potential Effects of Removing Domestic Livestock, particularly Sheep. Report to Department of the Environment, $88 \mathrm{pp}$.

Miles, J., Welch, D. \& Chapman, S. 1978. Vegetation and management in the uplands In: Upland Land Use in England and Wales, 77-95. Cheltenham, Countryside Commission, CCP 111. 
Morgan-Davies, C., Wilson, R. \& Waterhouse, T. 2015. Use or delight? History of conflicting hill land uses in Scotland. Scottish Geographical Journal, 131: 98122.

Moss, R. \& Miller, G.R. 1976. Production, dieback and grazing of heather (Calluna vulgaris) in relation to numbers of red grouse (Lagopus L. scoticus) and mountain hares (Lepus timidus) in North-east Scotland. Journal of Applied Ecology, 13: 369-377.

Peterson, D.J. \& Prasad, R. 1998. The biology of Canadian weeds. 109. Cytisus scoparius (L.) Link. Canadian Journal of Plant Science, 78: 497-504.

Pollock, M.L., Legg, C.J., Holland, J.P. \& Theobald, C.M. 2007. Assessment of expert opinion: seasonal sheep preference and plant response to grazing. Rangeland Ecology \& Management, 60: 125-135.

Preston, C.R., Pearman, D.A. \& Dines, T.D. 2002. New Atlas of the British and Irish Flora. Oxford: Oxford University Press.

Rao, S. 2011. A future for the Mar Lodge pinewoods. Scottish Forestry, 65: 38-41.

Rao, S. 2017. Effect of reducing red deer Cervus elaphus density on browsing impact and growth of Scots pine Pinus sylvestris seedlings in semi-natural woodland in the Cairngorms, UK. Conservation Evidence, 14: 22-26.

Rodwell, J.S. 1991. British Plant Communities. 2. Mires and heaths. Cambridge: Cambridge University Press.

Scott, D. 1998. Impact of red deer on a Scots pine plantation after removal of deer fencing. Scottish Forestry, 52: 8-13.

Smith, A.J.E. 2006. The moss flora of Britain and Ireland. Cambridge: Cambridge University Press.

Stace, C.A. 2010. New flora of the British Isles. $3^{\text {rd }}$ ed. Cambridge: Cambridge University Press.

Thompson, D.B.A., Hester, A.J. \& Usher, M.B. 1995. Heaths and Moorland: Cultural Landscapes. Edinburgh: Scottish Natural Heritage, 400 pp..

Watson, A., Miller, G.R. \& Green, F.H.W. 1966. Winter browning of heather (Calluna vulgaris) and other moorland plants. Transactions of the Botanical Society of Edinburgh, 40: 195-203.

Welch, D. \& Scott, D. 1995. Studies in the grazing of heather moorland in north-east Scotland. VI. 20-year trends in botanical composition. Journal of Applied Ecology, 32: 596-611.

Welch, D., Scott, D., Mitchell, R. \& Elston, D.A. 2006. Slow recovery of heather (Calluna vulgaris $\mathrm{L}$. (Hull.)) in Scottish moorland after easing of heavy grazing pressure from red deer Botanical Journal of Scotland, 58: 1-17.

Copyright retained by author(s). Published by BSBI under the terms of the Creative Commons Attribution 4.0 International Public License. 